\title{
Reflections on sustainability
}

\author{
In the coming months, Nature Sustainability will be publishing a series of World Views from diverse scholars to \\ stimulate further thinking and dialogue within the community.
}

T

he prominent 1972 report The Limits to Growth by Meadows and colleagues ${ }^{1}$ will be half a century old next year. We reflect on what has been achieved over these five decades. The core message in the report was that if the ongoing growth trends in world population, industrialization, pollution, food production and resource depletion continued unchecked, there would be declines in both population and industrial capacity within a hundred years. Although the term 'sustainability' does not appear in the report, throughout its pages, one can read words like sustain, sustaining and sustainable in relation to growth, actions, systems, and the like. In a way, it represented a major effort to show what sustainability means. Not free of controversy, the report sounded the alarm on the likely consequences of ignoring that the natural resources on which our lives depend are finite, and it helped to get the message across to the general public and policy makers. In the same year, the first ever world conference on the environment was held in Stockholm and led to the creation of the United Nations Environment Programme (UNEP). International cooperation later led to the 1987 Brundtland report Our Common Future by the $\mathrm{UN}^{2}$, which proposed environmental strategies to achieve sustainable development over time, followed by the 1992 Rio conference, also led by the UN, which declared sustainable development as an achievable goal worldwide.

Despite the growing support, achieving international cooperation for sustainable development soon appeared to be quite polarizing between the richer nations, the Global North, which were mostly concerned about the environmental impacts of their own growth, such as pollution and waste, and poorer countries, the Global South, focused on improving the living standards of their people and protecting their natural resources from foreign exploitation.

The Rio summit in 1992 led to a full plan of action to be implemented mostly by national governments in all areas in which humans have an impact on the natural world, known as Agenda 21 (ref. $\left.{ }^{3}\right)$. The next milestones for international cooperation on sustainable development were the UN Millennium declaration in 2000 (ref. ${ }^{4}$ ), in which countries agreed on the eight Millennium Development Goals, and the launch of Agenda 2030 by the UN in 2015 (ref. ${ }^{5}$ ), which announced the seventeen Sustainable Development Goals (SDGs). With just over 8 years remaining to meet the SDGs, there does not seem to be much room for optimism. Although the sustainable development discourse has advanced and national governments are increasingly concerned about the multiple environmental crises that are affecting the lives of many people around the world, environmental degradation continues to accelerate. Many experts and practitioners would argue that most of the interventions and solutions implemented so far are not necessarily addressing the root causes of man-made environmental change but rather look like a combination of provisional and not always coherent patches. It is unclear whether we are aiming for the summit or running on a treadmill. Certainly, given the rapid social and technological changes the world is undergoing, the target seems to be moving.

Alongside the evolution of international negotiations and political efforts, scholars working on sustainability have also evolved over time into a much wider and varied community. These experts focus on identifying what drives environmental pressures, where and why they are occurring and how severe the impacts are, as well as on proposing solutions to achieve more sustainable societies. Their work aims to unpack the complexity of human-natural interfaces, and they get to this work from diverse perspectives. One only needs to ask a few colleagues to realize how the vision of a sustainable society, or the path to it, can differ remarkably between scholars from different backgrounds and experiences among others, there are the champions of technology, knowledge or education; the proponents of radically different economic systems; those who want to change almost everything; and those who think that it all comes down to individual behaviour. Besides, the word sustainability seems to mean different things in different languages and cultures. The meaning can change simply in trying to answer the question of what is it to be sustained. Very few things are truly permanent; the world evolves and changes.

We feel that in the lead up to the 50th anniversary of The Limits to Growth and the launch of UNEP, it is worth pausing and reflecting on the efforts undertaken so far to set the world on a sustainable development path. To encourage such reflection within the community, we are publishing a series of World Views from a diverse group of scholars over the coming months. The first contribution in this series comes from Pamela Matson, who champions a system-oriented approach to problem solving as the path towards sustainability.

Far from being fully representative of the richness in the sustainability community, this series of articles aims at encouraging as many scholars and practitioners as possible to perhaps rethink the direction in which they want to proceed - eventually, we will need to get off that treadmill and start moving forward, even though our targets keep changing. The articles reflect the authors' views, and we hope that they will inspire further thinking and debate.

Finally, we want to be clear that the aim here is not to achieve scholarly consensus on what sustainability means or on what will move us towards it. The aim is, ultimately, to spur debate and engage all of those interested in a constructive dialogue to think about how to contribute to it more effectively.

Published online: 16 November 2021 https://doi.org/10.1038/s41893-021-00821-4

References

1. Meadows D. H., Meadows, D. L., Randers, J. \& Behrens, W. W. III The Limits to Growth (Universe Books, 1972).

2. Report of the World Commission on Environment and Development: Our Common Future (NGO Committee on Education, 1987); http://www.un-documents.net/wced-ocf.htm

3. Agenda 21 (UN, 1992); https://sustainabledevelopment.un.org/ outcomedocuments/agenda21

4. United Nations Millennium Declaration Resolution A/RES/55/2 (UN, 2000); https://undocs.org/A/RES/55/2

5. Transforming Our World: the 2030 Agenda for Sustainable Development (UN, 2015); https://sdgs.un.org/2030agenda 